\title{
Polymorphisms of TGFBR1, TLR4 are associated with prognosis of gastric cancer in a Chinese population
}

\author{
Bangshun He ${ }^{1,2 \dagger}$, Tao Xu ${ }^{1 \dagger}$, Bei Pan ${ }^{1}$, Yuqin Pan ${ }^{1,2}$, Xuhong Wang ${ }^{3}$, Jingwu Dong ${ }^{4}$, Huiling Sun ${ }^{1,2}$, Xueni Xu ${ }^{3}$, \\ Xiangxiang Liu' ${ }^{1}$ and Shukui Wang ${ }^{1,2^{*}}$
}

\begin{abstract}
Background: Helicobacter pylori (H. pylori)-induced gastric cancer is an intricate progression of immune response against H. pylori infection. IL-16, TGF- $\beta 1$ and TLR4 pathways were the mediators involved in the immune response. We hypothesized that genetic variations in genes of these pathways have potential susceptibility to gastric cancer risk, and predict clinical outcomes of patients.

Methods: To investigate the susceptibility and prognostic value of genetic variations of IL-16, TGFBR1 and TLR4 pathways to gastric cancer, we performed a case-control study combined a retrospective study in a Chinese population. Genotyping for all polymorphisms was based on the Sequenom's MassARRAY platform, and H. pylori infection was determined by using an immunogold testing kit.

Results: We found rs 10512263 CC genotype was found to be a decreased risk of gastric cancer (CC vs. TT: adjusted $\mathrm{OR}=0.54,95 \% \mathrm{Cl}$ 0.31-0.97); however, rs334348 GG genotype was associated with increased risk of gastric cancer (GG vs. AA: adjusted $O R=1.51,95 \% \mathrm{Cl} 1.05-2.18$ ). We found that carriers harboring rs $1927911 \mathrm{~A}$ allele (GA/AA) or rs 10512263 C allele (CT/CC) have unfavorable survival time than none carriers (rs1927911: GA/AA vs. GG: adjusted $\mathrm{HR}=1.27,95 \% \mathrm{Cl} 1.00-1.63 ;$ rs 10512263: CT/CC vs. TT: adjusted $\mathrm{HR}=1.29,95 \% \mathrm{Cl} 1.02-1.63$ ) and that individuals harboring both two minor alleles (rs1927911 GA/AA and rs10512263 CT/CC) suffered a significant unfavorable survival (adjusted $\mathrm{HR}=1.64,95 \% \mathrm{Cl} 1.17-2.31$ ).
\end{abstract}

Conclusion: In short, we concluded that two polymorphisms (rs334348, rs10512263) in TGFBR1 were associated with risk of gastric cancer, and that TLR4 rs 1927911 and TGFBR1 rs 10512263 were associated with clinical outcomes of gastric cancer patients.

Keywords: IL-16, TGFBR1, TLR4, Polymorphism, Gastric cancer, Susceptibility, Prognosis

\section{Background}

Gastric cancer is the fifth most common cancer worldwide and ranks third cause of cancer related mortality [1]. Almost over half of new diagnosed cases are from eastern Asian, predominantly in China [2]. Gastric cancer is a multifactorial disease with multistep etiology. Epidemiological studies have demonstrated that interaction

\footnotetext{
*Correspondence: sk_wang@njmu.edu.cn

${ }^{\dagger}$ Bangshun $\mathrm{He}$ and Tao Xu contributed equally to this study

${ }^{1}$ General Clinical Research Center, Nanjing First Hospital, Nanjing Medical

University, 68 Changle Road, Nanjing 210006, China

Full list of author information is available at the end of the article
}

of environmental factors, such as Helicobacter pylori (H. pylori) infection, excessive salt intake, alcohol drinking and tobacco smoking, and genetic background was regarded as risk of gastric cancer.

For environmental factors, $H$. pylori causing chronic inflammation has been verified as a key factor involved in gastric carcinogenesis. Moreover, for genetic background, polymorphisms in immune-related genes, such as $I L-1 B, I L-1 R N, I L-10$, could affect their expression and were suggested as risk factors of gastric cancer [3, 4]. In addition, we previously reported genetic polymorphisms in the promoter of $I L-1 B / I L-1 R N$ were the

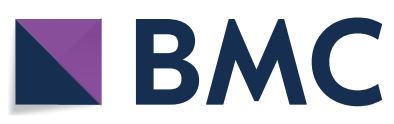

(c) The Author(s) 2018. This article is distributed under the terms of the Creative Commons Attribution 4.0 International License (http://creativecommons.org/licenses/by/4.0/), which permits unrestricted use, distribution, and reproduction in any medium, provided you give appropriate credit to the original author(s) and the source, provide a link to the Creative Commons license, and indicate if changes were made. The Creative Commons Public Domain Dedication waiver (http://creativecommons.org/ publicdomain/zero/1.0/) applies to the data made available in this article, unless otherwise stated. 
risk of gastric cancer [5, 6]. Of immune-related genes, IL-16 is a pro-inflammatory cytokine that has a variety of biological functions, playing role in the development and homeostasis of the immune system [7], and stimulating the secretion of tumor-associated inflammatory cytokines including TNF- $\alpha$, IL-1 $\beta$, IL-6, and IL-15 [8]. In addition, polymorphisms in $I L-16$ were investigated to be risk of various cancers, including gastric cancer, and the diagnostic and prognostic value of serum IL-16 levels for patients with gastric cancer was also reported [9]. Transforming growth factor beta-1 (TGF$\beta 1)$, a multifunctional cytokine, combined it's receptor (TGFBR1) plays biphasic role in carcinogenesis that, in early stages of cancer, it acts as a tumor suppressor by inhibiting cellular proliferation or by promoting cellular differentiation and apoptosis; in later stages of cancer, however, it turns to be a tumor promoter by stimulating angiogenesis and cell motility, suppressing immune response, and increasing progressive invasion and metastasis [10-12]. Moreover, serum TGF- $\beta 1$ levels implicating a predictive and prognostic value for patients with gastric cancer $[13,14]$ may indicate polymorphisms in genes of TGF- $\beta 1$ pathway including TGFBR1 could influence the risk and clinical progression of gastric cancer [15-17]. In the progression of H. pylori infection, toll-like receptors (TLRs), a group of membrane-bound receptors proteins, play a pivotal role in innate immune response and provide first line of host defense. Among TLRs, TLR-4 is the main receptor of lipopolysaccharide (LPS) and plays a role in initiating the inflammatory response of $H$. pylori infection. After binding of microbial ligands, a dysregulation of TLR signalling may contribute to an unbalanced ratio between pro- and anti-inflammatory cytokines, resulting in increasing higher risk of developing gastric cancer [18]. Similarly, polymorphisms in TLR4 has been implicated as risk factors for gastric cancer [18]; however, the conclusion of susceptibility of these polymorphisms to gastric cancer risk remains elusive [19-21].

Immune response triggered by $H$. pylori infection, including host adaptive immune response (such as IL-1b, TNF-a, IL-10, IL-16) and innate immune response (such as TLR4), is an intricate progression, which is responsible for clinical outcomes of individuals with $H$. pylori infection. Thus, polymorphisms occurring in immune genes could serves as possible susceptibility factors to the development of gastric cancer and have a predictive value for gastric cancer clinical outcome. Here, we conducted a case-control study to assess the susceptibility of polymorphisms in $I L-16$, TGFBR1 and TLR4 to risk of gastric cancer in a Chinese population, and the prognostic value of the polymorphisms was also evaluated by a retrospective study.

\section{Materials and methods Study population}

For the case-controls study, we recruited 479 patents histologically diagnosed as gastric cancer and 483 age- and sex-matched healthy controls who came to the hospital for routine physical examination. The demographic features of participants were collected via a questionnaire or by reviewing patients' medical records. The TNM stages were classified according to American Joint Commission for Cancer Staging in 2002 (the sixth edition). For retrospective study, we traced survival state of all patients through on-site interview, direct calling or medical chart review, and finally, a total of 460 patients were followed up to 5 years. The protocol of this study was approved by the Institutional Review Board of the Nanjing First Hospital, and written informed consents were obtained from all participants.

\section{DNA extraction and genotyping}

We retrieved the potential genetic variations in $I L-16$, TGF-BR1 and TLR4 from the National Center for Biotechnology Information dbSNP database (http://www. ncbi.nlm.nih.gov/projects/SNP), and then the genetic variations were selected followed the following criteria: (1) the minor allele frequency (MAF) is not less than 5\% in Han Chinese population; (2) with position in exons, promoter region, $5^{\prime}$ untranslated regions (UTR) or $3^{\prime}$ UTR; and (3) published results shown to be associated with any cancer risk. For those polymorphisms in intron if meet the criterion (3) were also included. Finally, a total of 11 polymorphisms were selected (Additional file 1: Table S1).

The DNA extraction and genotyping was performed as we previously described [22]. A GoldMag-Mini Whole Blood Genomic DNA Purification Kit (GoldMag Co. Ltd. Xi'an, China) was used for DNA extraction, and then the genotyping was performed on the SequenomMassARRAY platform.

\section{H. pylori infection detection}

To identify the $H$. pylori infection, the serum of all participants were collected to detect $H$. pylori antibody by using a $H$. pylori immunogold testing kit (KangmeiTianhong Biotech Co., Ltd, Beijing, China).

\section{Statistical analysis}

The difference of demographic features of the two groups was assessed by $t$ test or $\chi^{2}$ test. For the distribution of genotypes, a goodness of fit Chi square test was adopted to test the Hardy-Weinberg equilibrium (HWE) in the control group, and then, the susceptibility of polymorphisms to gastric cancer risk was expressed with odds ratios (ORs) and 95\% confidence intervals 
(CIs). Subgroups analyze was conducted if there was a significant association of the polymorphism to gastric cancer risk. The risk of polymorphisms was calculated by using a logistic regression model based on SAS v9.1 (SAS Institute, Cary, NC, USA). The hazard ratios (HRs) of genotypes to survival time of patients were calculated by Cox regression analysis with SPSS 11.0 (SPSS, Chicago, IL, USA). The $\mathrm{p}$ value $<0.05$ was considered statistically significant difference.

\section{Result}

\section{Characteristics of the study population}

The health controls and patients were matched for age $(p=0.748)$ and gender $(p=0.881)$. There were significant differences between the two groups with respect to the frequency of $H$. pylori infection $(\mathrm{p}=0.039)$, cigarette smoking $(\mathrm{p}<0.001)$ and alcohol consumption $(\mathrm{p}<0.001)$, summarized in Additional file 1: Table S2. The observed frequencies of all tested genotypes in controls did not deviate from HWE (shown in Additional file 1: Table S1).

\section{Association between polymorphisms and risk of gastric cancer}

Two polymorphisms in TGFBR1 were observed to be potentially associated with risk of gastric cancer. rs10512263 CC genotype was found to be a decreased risk of gastric cancer (CC vs. TT: adjusted $\mathrm{OR}=0.54$, 95\% CI 0.31-0.97, $\mathrm{p}=0.039$ ); however, rs334348 GG genotype was associated with increased risk of gastric cancer (GG vs. AA: adjusted OR=1.51, 95\% CI 1.05-2.18, $\mathrm{p}=0.028)$, shown in Table 1 .

Stratified analysis by age, gender, H. pylori infection status, tumor stage and tumor site revealed that the significant association of rs10512263 to risk of gastric cancer was maintained in the subgroup of male, and subgroup of individuals with older age, shown in Table 2. In the stratification analysis by pathologic characteristics, we observed that the significant association of rs 334348 to risk of gastric cancer was maintained in the subgroup of patients with clinical stage T1-T2. In addition, although no significant association was found, aboundary significant of two polymorphisms to risk of gastric cancer was observed in subgroup of clinical stage T1-T2 and in subgroup of non-cardiac, shown in Table 3.

\section{Association between polymorphisms and clinical outcome}

A retrospective study was conducted based on 460 patients with follow-up information on survival period of 5 years. We found that carriers harboring rs1927911 A allele (GA/AA) or rs10512263 C allele (CT/CC) have unfavorable survival time than none carriers (rs1927911: GA/AA vs. GG: adjusted $\mathrm{HR}=1.27,95 \%$
CI 1.00-1.63, $\mathrm{p}=0.054$; rs10512263: CT/CC vs. TT: adjusted $\mathrm{HR}=1.29,95 \% \mathrm{CI} 1.02-1.63, \mathrm{p}=0.031$ ), shown in Table 4.

The stratified analysis based on the age, gender, tumor site or clinical stage was also performed for the significant polymorphisms, and the result revealed that carriers with rs1927911 A allele have poor survival in subgroup of patients with age younger than 64 years old (GA/AA vs. GG: adjusted $\mathrm{HR}=1.64,95 \% \mathrm{CI} 1.13-2.38$ ), male (GA/ AA vs. GG: adjusted $H R=1.36,95 \% \mathrm{CI} 1.03-1.81$ ), and non-cardiac gastric cancer (GA/AA vs. GG: adjusted $\mathrm{HR}=1.34,95 \% \mathrm{CI} 1.00-1.80$ ), and that rs1927911 A allele carriers have poor survival in the subgroup of male (CT/CC vs. TT: adjusted $\mathrm{HR}=1.43,95 \% \mathrm{CI} 1.09-1.87$ ), patients in clinical stage T1-T2 (CT/CC vs. TT: adjusted $\mathrm{HR}=2.54,95 \% \mathrm{CI} 1.38-4.69)$, and non-cardiac gastric cancer (NCGC) (CT/CC vs. TT: adjusted $\mathrm{HR}=1.36,95 \%$ CI 1.02-1.80), shown in Table 5.

To identify the impact of the co-occurrence of rs1927911 and rs10512263 on overall survival, we analyzed the association between locus-locus interaction and overall survival, and the result shown that individuals harboring both two minor alleles (rs1927911GA/AA and rs10512263CT/CC) suffered a significant unfavorable survival (adjusted HR $=1.64,95 \%$ CI 1.17-2.31), shown in Table 6.

\section{Discussion}

This case-control study combined retrospective study observed that two polymorphisms (rs334348, rs10512263) in TGFBR1 were associated with risk of gastric cancer, and that rs1927911and rs10512263 were associated with survival of gastric cancer patients.

TGFBR1 rs6478974 is a genetic variation in intron 1, it was previously reported to be associated with microRNAs expression and involved in carcinogenesis [23]. In addition, the significant association of rs6478974 to gastric cancer risk was also reported [15]; however, in this study, we observed such a significant association in the subgroup of male but for all participants, indicating male carrying rs6478974 polymorphisms have higher gastric cancer risk than female. Another polymorphism rs10512263 locating intron 1 of TGBR1 was observed as a susceptibility of gastric cancer in this study; however, an opposite result was also reported [15]. It is noted that, in the subgroup analysis, we observed that the decreased risk of the polymorphism to gastric cancer was maintained in the subgroup of male, and those with age older than 64 years, suggesting the susceptibility of the polymorphism to gastric cancer risk could be effected by demographic characteristics of participants. Due to the limited sample sized of this study, the significant should be verified by further study. TGFBR1 rs334348 located in 
Table 1 Association between polymorphisms and risk of gastric cancer

\begin{tabular}{|c|c|c|c|c|c|c|}
\hline Polymorphism & Genotype & Cases, n (\%) & Controls, n (\%) & OR $(95 \% \mathrm{Cl})$ & OR $(95 \% \mathrm{Cl})^{\mathrm{a}}$ & $p$ value \\
\hline \multirow[t]{5}{*}{ IL-16 rs4072111 } & CC & 334 (69.73) & $345(71.43)$ & Reference & Reference & \\
\hline & $\mathrm{TC}$ & $126(26.30)$ & $122(25.26)$ & $1.07(0.80,1.43)$ & $1.01(0.75,1.36)$ & 0.970 \\
\hline & $\mathrm{TT}$ & $19(3.97)$ & $16(3.31)$ & $1.23(0.62,2.43)$ & $1.20(0.60,2.41)$ & 0.600 \\
\hline & $\mathrm{TC} / \mathrm{TT}$ & $145(30.27)$ & $138(28.57)$ & $1.09(0.82,1.43)$ & $1.02(0.77,1.36)$ & 0.870 \\
\hline & Additive model & & & $1.08(0.86,1.37)$ & $1.04(0.82,1.32)$ & 0.755 \\
\hline \multirow[t]{5}{*}{ rs4778889 } & TT & $267(55.74)$ & $266(55.07)$ & Reference & Reference & \\
\hline & $\mathrm{CT}$ & $182(38.00)$ & $192(39.75)$ & $0.94(0.73,1.23)$ & $0.92(0.70,1.20)$ & 0.524 \\
\hline & CC & $30(6.26)$ & $25(5.18)$ & $1.20(0.68,2.09)$ & $1.19(0.68,2.10)$ & 0.542 \\
\hline & $\mathrm{CT} / \mathrm{CC}$ & $212(44.26)$ & 217 (44.93) & $0.97(0.76,1.26)$ & $0.95(0.73,0.23)$ & 0.688 \\
\hline & Additive model & & & $1.01(0.82,1.25)$ & $1.00(0.81,1.23)$ & 0.965 \\
\hline \multirow[t]{5}{*}{ rs859 } & $\mathrm{TT}$ & $129(26.93)$ & $124(25.67)$ & Reference & Reference & \\
\hline & $\mathrm{CT}$ & 235 (49.06) & $248(51.35)$ & $0.91(0.67,1.24)$ & $0.88(0.64,1.20)$ & 0.406 \\
\hline & $\mathrm{CC}$ & $115(24.01)$ & $111(22.98)$ & $1.00(0.70,1.43)$ & $0.98(0.68,1.41)$ & 0.899 \\
\hline & $\mathrm{CT} / \mathrm{CC}$ & $350(73.07)$ & 359 (74.33) & $0.94(0.70,1.25)$ & $0.92(0.68,1.23)$ & 0.551 \\
\hline & Additive model & & & $1.00(0.83,1.19)$ & $0.98(0.82,1.18)$ & 0.859 \\
\hline \multirow[t]{5}{*}{ rs11556218 } & $\mathrm{TT}$ & $306(63.88)$ & $308(63.77)$ & Reference & Reference & \\
\hline & GT & $151(31.52)$ & $157(32.51)$ & $1.97(0.74,1.27)$ & $0.93(0.71,1.23)$ & 0.628 \\
\hline & GG & $22(4.59)$ & $18(3.73)$ & $1.23(0.65,2.34)$ & $1.29(0.68,2.48)$ & 0.439 \\
\hline & GT/GG & $173(36.12)$ & $175(36.23)$ & $1.00(0.77,1.29)$ & $0.97(0.94,1.27)$ & 0.820 \\
\hline & Additive model & & & $1.02(0.82,1.28)$ & $1.01(0.81,1.27)$ & 0.913 \\
\hline \multirow[t]{5}{*}{ rs1131445 } & $\mathrm{TT}$ & $221(46.14)$ & $210(43.48)$ & Reference & Reference & \\
\hline & $\mathrm{CT}$ & $211(44.05)$ & $222(45.96)$ & $0.90(0.69,1.18)$ & $0.94(0.72,1.23)$ & 0.655 \\
\hline & CC & $47(9.81)$ & $51(10.56)$ & $0.88(0.57,1.36)$ & $0.93(0.59,1.46)$ & 0.748 \\
\hline & CT/CC & $258(53.86)$ & $273(56.52)$ & $0.90(0.70,1.16)$ & $0.93(0.72,1.21)$ & 0.592 \\
\hline & Additive model & & & $0.92(0.76,1.12)$ & $0.95(0.78,1.16)$ & 0.618 \\
\hline \multirow[t]{5}{*}{ TLR4 rs 10759932} & $\mathrm{TT}$ & $240(50.10)$ & $251(51.97)$ & Reference & Reference & \\
\hline & $\mathrm{TC}$ & $191(39.87)$ & $196(40.58)$ & $1.02(0.78,1.33)$ & $1.05(0.80,1.38)$ & 0.733 \\
\hline & CC & $48(10.02)$ & $36(7.45)$ & $1.39(0.87,2.22)$ & $1.38(0.86,2.23)$ & 0.184 \\
\hline & $\mathrm{TC} / \mathrm{CC}$ & 239 (49.90) & $232(48.03)$ & $1.08(0.84,1.39)$ & $1.10(0.85,1.42)$ & 0.481 \\
\hline & Additive model & & & $1.11(0.91,1.35)$ & $1.12(0.92,1.36)$ & 0.275 \\
\hline \multirow[t]{5}{*}{ rs1927911 } & GG & $171(35.70)$ & $175(36.23)$ & Reference & Reference & \\
\hline & GA & $226(47.18)$ & $226(46.79)$ & $1.02(0.77,1.35)$ & $1.04(0.78,1.38)$ & 0.801 \\
\hline & AA & $82(17.12)$ & $82(16.98)$ & $1.02(0.71,1.48)$ & $0.99(0.68,1.45)$ & 0.967 \\
\hline & GA/AA & $308(64.30)$ & $308(63.77)$ & $1.02(0.79,1.33)$ & $1.03(0.79,1.34)$ & 0.844 \\
\hline & Additive model & & & $1.01(0.85,1.21)$ & $1.01(0.84,1.21)$ & 0.930 \\
\hline \multirow[t]{5}{*}{ rs11536889 } & GG & $303(63.26)$ & $293(60.66)$ & Reference & Reference & \\
\hline & $C G$ & $156(32.57)$ & $166(34.37)$ & $0.91(0.69,1.19)$ & $0.91(0.69,1.19)$ & 0.477 \\
\hline & $C C$ & $20(4.18)$ & $24(4.97)$ & $0.81(0.44,1.49)$ & $0.76(0.40,1.43)$ & 0.392 \\
\hline & $\mathrm{CG} / \mathrm{CC}$ & $176(36.74)$ & 190 (39.34) & $0.90(0.69,1.16)$ & $0.89(0.69,1.16)$ & 0.402 \\
\hline & Additive model & & & $0.90(0.73,1.13)$ & $0.90(0.72,1.12)$ & 0.355 \\
\hline \multirow[t]{5}{*}{ TGF-BR1 rs6478974 } & $\mathrm{TT}$ & $219(45.72)$ & $194(40.17)$ & Reference & Reference & \\
\hline & AT & $204(42.59)$ & $220(45.55)$ & $0.82(0.63,1.08)$ & $0.80(0.61,1.06)$ & 0.118 \\
\hline & AA & $56(11.69)$ & $69(14.29)$ & $0.72(0.48,1.08)$ & $0.68(0.45,1.02)$ & 0.063 \\
\hline & AT/AA & $260(54.28)$ & $289(59.83)$ & $0.80(0.62,1.03)$ & $0.78(0.60,1.01)$ & 0.055 \\
\hline & Additive model & & & $0.84(0.70,1.01)$ & $0.82(0.68,0.99)$ & 0.038 \\
\hline
\end{tabular}


Table 1 (continued)

\begin{tabular}{|c|c|c|c|c|c|c|}
\hline Polymorphism & Genotype & Cases, n (\%) & Controls, n (\%) & OR $(95 \% \mathrm{Cl})$ & OR $(95 \% \mathrm{Cl})^{\mathrm{a}}$ & $p$ value \\
\hline \multirow[t]{5}{*}{ rs334348 } & AA & $143(29.85)$ & 158 (32.71) & Reference & Reference & \\
\hline & $A G$ & $221(46.14)$ & $240(49.69)$ & $1.02(0.76,1.36)$ & $1.05(0.78,1.42)$ & 0.730 \\
\hline & GG & 115 (24.01) & $85(17.60)$ & $1.50(1.04,2.14)$ & $1.51(1.05,2.18)$ & 0.028 \\
\hline & $A G / G G$ & $336(70.15)$ & 325 (69.29) & $1.14(0.87,1.50)$ & $1.17(0.89,1.55)$ & 0.263 \\
\hline & Additive model & & & $1.20(1.01,1.43)$ & $1.22(1.02,1.46)$ & 0.032 \\
\hline \multirow[t]{5}{*}{ rs10512263 } & $\mathrm{TT}$ & $279(58.25)$ & $262(54.24)$ & Reference & Reference & \\
\hline & $C T$ & 178 (37.16) & 187 (38.72) & $0.89(0.69,1.17)$ & $0.87(0.66,1.14)$ & 0.297 \\
\hline & CC & $22(4.59)$ & $34(7.04)$ & $0.61(0.35,1.07)$ & $0.54(0.37,0.97)$ & 0.039 \\
\hline & $\mathrm{CT} / \mathrm{CC}$ & $200(41.75)$ & $221(45.76)$ & $0.85(0.66,1.10)$ & $0.82(0.63,1.06)$ & 0.127 \\
\hline & Additive model & & & $0.84(0.68,1.03)$ & $0.81(0.65,1.00)$ & 0.047 \\
\hline
\end{tabular}

Italic represents any values with $\mathrm{p}<0.05$

$O R$ odds ratio

a Adjusted for age, gender, smoking, drinking, and H. pylori infection status

the $3^{\prime}$ UTR region, and it was suggested with location in miRNA-628-5p binding site, resulting in GG genotype turn to be associated with lower TGFBR1 expression [24]. In addition, previous study has also reported that it could confer an increased risk of colorectal cancer by affecting TGFBR1 expression [25].

In the retrospective study, we observed TLR4 rs1927911 and TGFBR1 rs10512263 were associated with clinical outcomes of gastric cancer patients. TLR4 rs1927911 is an intron variation that was previously reported as a protective factor for gastric cancer [26, 27]; however, we failed to find such a significant association but we observed it was associated with unfavorable OS of gastric cancer patients, especially for male, patients with age younger than 64 years old, or patients with NCGC. To date, the function of rs1927911 remains unclear, we speculated that such a significant association was related the microenvironment of cancer by that TLR4 signaling was involved in drug resistant by inducing the M1 phenotype macrophages [28] and by that TLR4/NF- $\mathrm{kB}$ signal pathway mediated uncontrolled inflammation [29]. Moreover, this study observed TGFBR1 rs10512263 has a predictive value for clinical outcomes of gastric cancer patients. Although the function of rs10512263 remains unclear, TGF- $\beta$ signaling has been suggested to promote gastric cancer progression by enhancing motility and inducing invasiveness of gastric cancer cell [11], or by promoting tumor vasculature conformation [30], which could be partly explained for the predictive role of TGFBR1 rs10512263 in gastric cancer patients.
Polymorphisms in three immune related genes was discussed for their susceptibility and predictive role in gastric cancer. Here, some limitations of this study should be noted. Firstly, the function of these polymorphisms is largely unclear, and we failed to assess the association of polymorphism and TGFBR1, TLR4 expression in patients. Instead of that, to perform functional candidate polymorphism and expression quantitative trait locus (eQTL) analyses on the promising genes, we mined the data from the following databases: GTExPortal (https:// www.gtexportal.org/home/) and Haploreg (http://www. broadinstitute.org/mammals/haploreg/haploreg.php), and the results shown that TLR4 rs1927911, TGF-BR1 rs6478974 and rs334348 could affect their corresponding gene expression, and that TGF-BR1 rs10512263 could regulate certain motifs, which were consistent to our results, see Additional file 2: Figures S1 and S2. Secondly, the sample size of this study was not large enough, which may weaken the statistical power. Thirdly, environmental factors, such as diet, physical exercises, gastric diseases history, and subtype of $H$. pylori were not included in this study, which may influence the conclusion. Finally, there are number of polymorphisms in the immune related genes, here we selected three of them and some more immune related genes required to be discussed.

\section{Conclusion}

We concluded that two polymorphisms (rs334348, rs10512263) in TGF-BR1 were associated with risk of gastric cancer, and that TLR4 rs1927911 and TGFBR1 


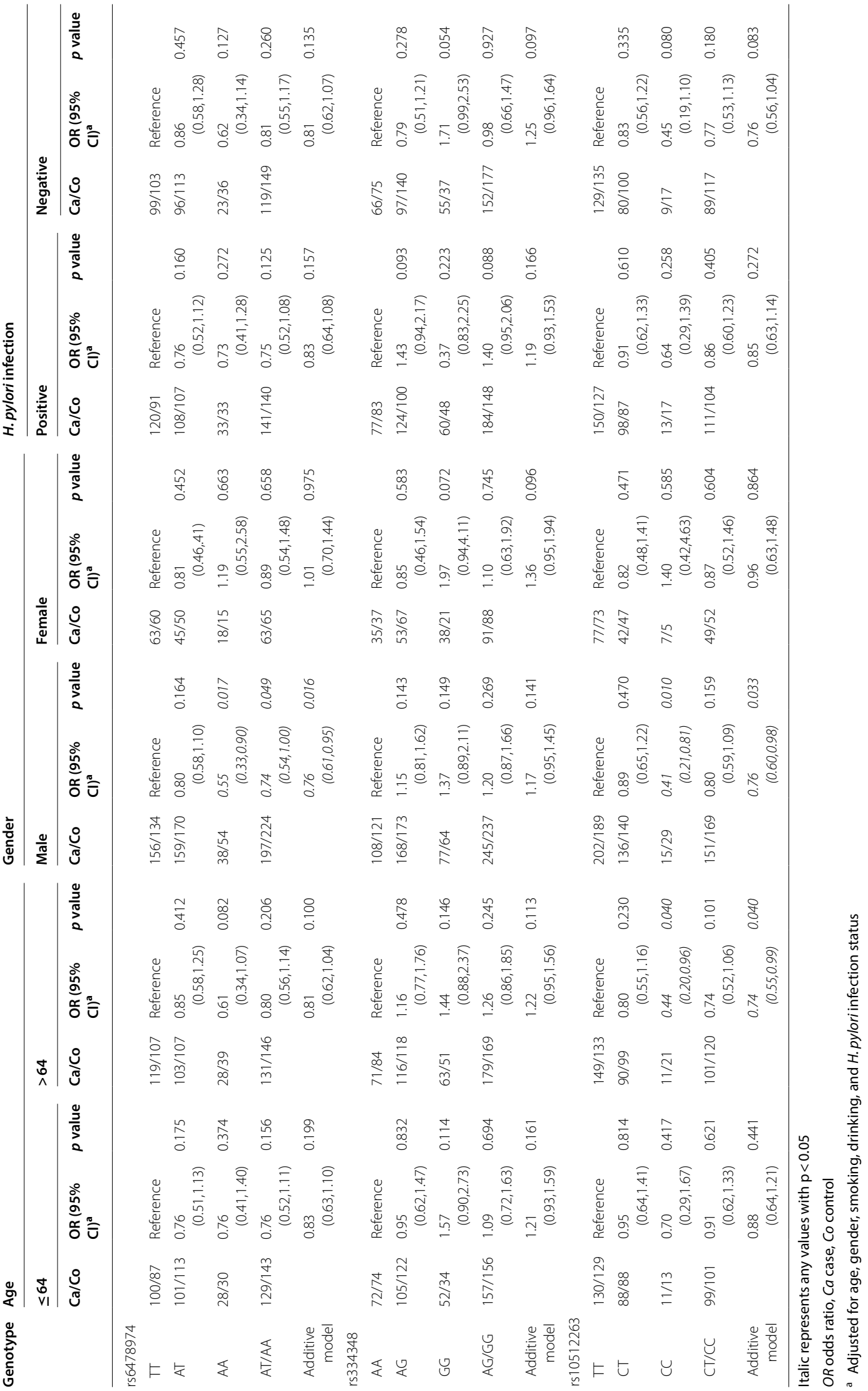




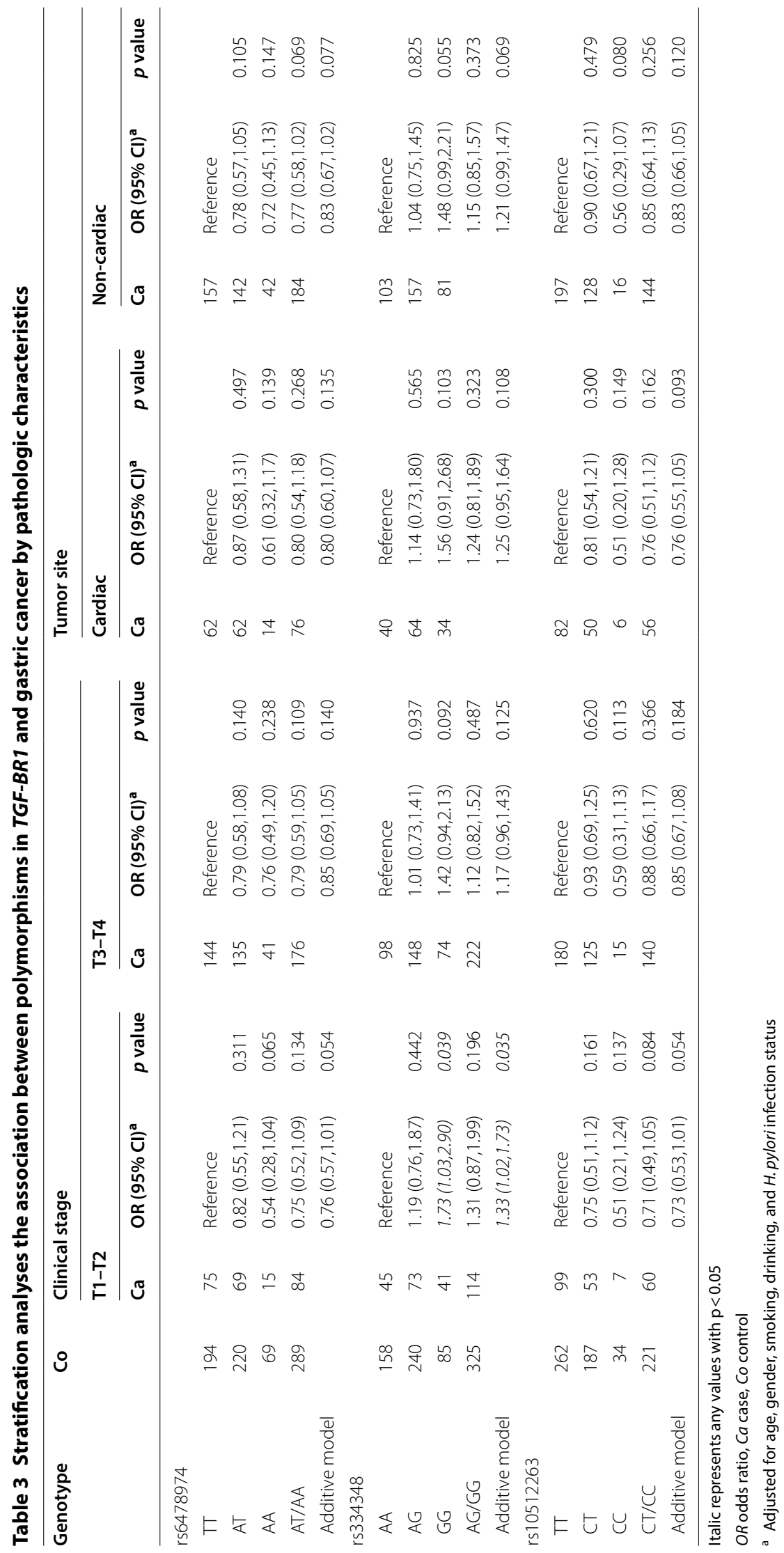


Table 4 Association between polymorphism and overall survival of gastric cancer patients in co-dominant model

\begin{tabular}{|c|c|c|c|c|c|c|}
\hline Genotype & Cases, $\mathbf{n}$ & Death, n (\%) & Log-rank p-value & HR & $\mathrm{HR}(95 \% \mathrm{Cl})^{\mathrm{a}}$ & $p$-value \\
\hline \multicolumn{7}{|l|}{ rs4072111 } \\
\hline $\mathrm{CC}$ & 322 & $205(0.64)$ & & Reference & Reference & \\
\hline $\mathrm{TC} / \mathrm{TT}$ & 138 & $81(0.59)$ & 0.344 & $0.88(0.68,1.14)$ & $1.12(0.86,1.45)$ & 0.408 \\
\hline \multicolumn{7}{|l|}{ rs4778889 } \\
\hline $\mathrm{TT}$ & 256 & $172(0.67)$ & & Reference & Reference & \\
\hline CT/CC & 204 & $114(0.56)$ & 0.028 & $0.77(0.61,0.97)$ & $0.84(0.66,1.06)$ & 0.146 \\
\hline \multicolumn{7}{|l|}{ rs11556218 } \\
\hline $\mathrm{TT}$ & 293 & $192(0.66)$ & & Reference & Reference & \\
\hline $\mathrm{GT} / \mathrm{GG}$ & 167 & $94(0.56)$ & 0.110 & $0.82(0.64,1.05)$ & $0.94(0.73,1.20)$ & 0.607 \\
\hline \multicolumn{7}{|l|}{ rs859 } \\
\hline AA & 109 & $68(0.62)$ & & Reference & Reference & \\
\hline GA/GG & 351 & $218(0.62)$ & 0.633 & $1.07(0.81,1.40)$ & $1.03(0.79,1.36)$ & 0.814 \\
\hline \multicolumn{7}{|l|}{ rs1131445 } \\
\hline TT & 211 & $127(0.60)$ & & Reference & Reference & \\
\hline $\mathrm{CT} / \mathrm{CC}$ & 249 & $159(0.64)$ & 0.150 & $1.18(0.94,1.50)$ & $1.06(0.84,1.35)$ & 0.617 \\
\hline \multicolumn{7}{|l|}{ rs10759932 } \\
\hline $\mathrm{TT}$ & 231 & $141(0.61)$ & & Reference & Reference & \\
\hline $\mathrm{TC} / \mathrm{CC}$ & 229 & $145(0.63)$ & 0.563 & $1.07(0.85,1.35)$ & $1.07(0.84,1.35)$ & 0.588 \\
\hline \multicolumn{7}{|l|}{ rs1927911 } \\
\hline GG & 165 & $95(0.58)$ & & Reference & Reference & \\
\hline GA/AA & 295 & $191(0.65)$ & 0.113 & $1.22(0.95,1.56)$ & $1.27(1.00,1.63)$ & 0.054 \\
\hline \multicolumn{7}{|l|}{ rs11536889 } \\
\hline GG & 293 & $181(0.62)$ & & Reference & Reference & \\
\hline $\mathrm{CG} / \mathrm{CC}$ & 167 & $105(0.63)$ & 0.957 & $1.01(0.79,1.28)$ & $0.99(0.77,1.26)$ & 0.924 \\
\hline \multicolumn{7}{|l|}{ rs6478974 } \\
\hline $\mathrm{TT}$ & 212 & $126(0.59)$ & & Reference & Reference & \\
\hline TA/AA & 248 & $160(0.65)$ & 0.224 & $1.16(0.92,1.46)$ & $1.23(0.98,1.56)$ & 0.079 \\
\hline \multicolumn{7}{|l|}{ rs334348 } \\
\hline GG & 110 & $64(0.58)$ & & Reference & Reference & \\
\hline $\mathrm{AG} / \mathrm{AA}$ & 350 & $222(0.63)$ & 0.491 & $1.10(0.84,1.46)$ & $1.04(0.79,1.38)$ & 0.787 \\
\hline \multicolumn{7}{|l|}{ rs10512263 } \\
\hline $\mathrm{TT}$ & 269 & $157(0.58)$ & & Reference & Reference & \\
\hline $\mathrm{CT} / \mathrm{CC}$ & 191 & $129(0.68)$ & 0.031 & $1.29(1.02,1.63)$ & $1.29(1.02,1.63)$ & 0.031 \\
\hline
\end{tabular}

Italic represents any values with $\mathrm{p}<0.05$

a Adjusted for age, sex, tumor site and TNM stage 
Table 5 Subgroup analyses of association between polymorphisms and survival in co-dominant model

\begin{tabular}{|c|c|c|c|c|c|c|c|c|}
\hline \multirow[t]{2}{*}{ Group } & \multirow[t]{2}{*}{ Case, $\mathrm{n}$} & \multirow[t]{2}{*}{ Death, n (\%) } & \multicolumn{3}{|l|}{ rs1927911 } & \multicolumn{3}{|c|}{ rs10512263 } \\
\hline & & & GA/AA: GG & $\mathrm{HR}(95 \% \mathrm{Cl})^{\mathrm{a}}$ & p-value & CT/CC:TT & $\mathrm{HR}(95 \% \mathrm{Cl})^{\mathrm{a}}$ & P-value \\
\hline \multicolumn{9}{|l|}{ Age } \\
\hline$<64$ & 224 & $130(0.58)$ & $142 / 82$ & $1.64(1.13,2.38)$ & 0.009 & $97 / 127$ & $1.34(0.95,1.90)$ & 0.099 \\
\hline$\geq 64$ & 236 & $156(0.66)$ & $153 / 83$ & $1.04(0.75,1.45)$ & 0.817 & $94 / 142$ & $1.19(0.86,1.64)$ & 0.286 \\
\hline \multicolumn{9}{|l|}{ Gender } \\
\hline Male & 338 & $214(0.63)$ & $216 / 122$ & $1.36(1.03,1.81)$ & 0.033 & $145 / 193$ & $1.43(1.09,1.87)$ & 0.010 \\
\hline Female & 122 & $72(0.64)$ & $79 / 43$ & $1.08(0.65,1.80)$ & 0.754 & $46 / 76$ & $1.26(0.76,2.08)$ & 0.365 \\
\hline \multicolumn{9}{|l|}{ Clinical stage } \\
\hline $\mathrm{T} 1-\mathrm{T} 2$ & 159 & $42(0.26)$ & $102 / 57$ & $1.36(0.70,2.66)$ & 0.367 & $60 / 99$ & $2.61(1.40,4.86)$ & 0.003 \\
\hline T3-T4 & 301 & $244(0.81)$ & $193 / 108$ & $1.21(0.93,1.58)$ & 0.160 & $131 / 170$ & $1.04(0.80,1.34)$ & 0.784 \\
\hline \multicolumn{9}{|l|}{ Tumor site } \\
\hline Cardiac & 132 & $87(0.66)$ & $91 / 41$ & $1.07(0.67,1.71)$ & 0.768 & $54 / 78$ & $1.47(0.94,2.31)$ & 0.094 \\
\hline Non-cardiac & 328 & $199(0.61)$ & $204 / 124$ & $1.34(1.00,1.80)$ & 0.050 & $137 / 191$ & $1.36(1.02,1.80)$ & 0.034 \\
\hline
\end{tabular}

Italic represents any values with $\mathrm{p}<0.05$

a Adjusted for age, sex, tumor site and TNM stage

Table 6 Locus-locus interactions between rs 1927911 and rs 10512263 and survival

\begin{tabular}{llccccc}
\hline rs1927911 & rs10512263 & Cases, $\mathbf{n}$ & Death, $\mathbf{n}(\%)$ & Log-rank $\mathbf{p}$ value & HR (95\% CI) $^{\mathbf{a}}$ & p-value \\
\hline GG & TT & 100 & $53(53.00)$ & 0.018 & Reference \\
GG & CT/CC & 65 & $42(64.42)$ & & $1.18(0.79,1.03)$ & 0.421 \\
GA/AA & TT & 169 & $104(61.54)$ & & $1.20(0.86,1.67)$ & 0.279 \\
GA/AA & CT/CC & 126 & $87(69.05)$ & & $1.64(1.17,2.31)$ & 0.005 \\
\hline
\end{tabular}

Italic represents any values with $\mathrm{p}<0.05$

a Adjusted for age, sex, tumor site and TNM stage

rs10512263 were associated with clinical outcomes of gastric cancer patients. This is a study firstly discussed the relation of polymorphisms in genes of $I L-16, T G F B R 1$ and TLR4 pathways and survival time of gastric cancer patients in Chinese population and our study could provide epidemiology data for further study.

\section{Additional files}

Additional file 1: Table S1. Information of enrolled genetic variations. Table S2. Clinical and demographic characteristics of enrolled participants.

Additional file 2: Figure S1. eQTL analysis of mRNA expression in whole blood and genotype data. A: TLR4 rs1927911, p-value =0.000016; B: TGF$B R 1$ rs6478974, p-value $=6.5 e-7$, and C: rs334348, p-value $=0.0000029$.

Figure S2. Results from the Haploreg website for the TGF-BR1 rs 10512263.

\section{Abbreviations}

TGF- $\beta 1$ : transforming growth factor beta- 1 ; TGFBR 1 : TGF- $\beta$ receptor $1 ; H$. pylori: Helicobacter pylori; TLRs: toll-like receptors; LPS: lipopolysaccharide; MAF: minor allele frequency; $5^{\prime}$ UTR: $5^{\prime}$ untranslated regions; OR: odds ratios; $\mathrm{Cl}$ : confidence intervals; HR: hazard ratios; HWE: Hardy-Weinberg equilibrium; NCGC: non-cardiac gastric cancer.

Authors' contributions

$\mathrm{BH}$ and SW designed this study; TX, BP and YP collected the sample and data; $\mathrm{XW}, \mathrm{JD}$ analyzed the date; $\mathrm{TX}, \mathrm{BP}$ and $\mathrm{XL}$ conducted the experiments. $\mathrm{BH}, \mathrm{SW}$ wrote the paper. All authors have reviewed the final version of the manuscript and approved to submit to your journal. All authors read and approved the final manuscript.

\section{Author details}

${ }^{1}$ General Clinical Research Center, Nanjing First Hospital, Nanjing Medical University, 68 Changle Road, Nanjing 210006, China. ${ }^{2}$ Helicobacter pylori Research Key Laboratory, Nanjing Medical University, Nanjing 210000, China.

${ }^{3}$ Medical College, Southeast University, Nanjing 210000, China. ${ }^{4}$ Digestive

Department, Xuyi People's Hospital, Huaian 211700, China.

\section{Acknowledgements}

Not applicable.

\section{Competing interests}

The authors declare that they have no competing interests.

\section{Availability of data and materials}

The data of the study are available from the corresponding author on reasonable request. 


\section{Consent for publication \\ Not applicable.}

\section{Ethics approval and consent to participate}

The study has acquired approval of the Institutional Review Board of the Nanjing First Hospital, and all enrolled participants or their representatives signed the informed consent according to relevant regulations. All participants signed informed consent in the study.

\section{Funding}

This study was supported by grants from Jiangsu 333 High-level Talents Cultivating Project to B. H (No. BRA201702), Jiangsu Provincial Medical Youth Talent to B.H (QNRC2016066) and Y.P (QNRC2016074), Innovation team of Jiangsu provincial health-strengthening engineering by science and education (CXTDB2017008), and Nanjing Medical University Science and Technique Development Foundation Project to HL.S (No. 2015NJMUZD049).

\section{Publisher's Note}

Springer Nature remains neutral with regard to jurisdictional claims in published maps and institutional affiliations.

Received: 11 September 2018 Accepted: 9 November 2018 Published online: 20 November 2018

\section{References}

1. Global Burden of Disease Cancer C, Fitzmaurice C, Dicker D, Pain A, Hamavid $\mathrm{H}$, Moradi-Lakeh M, Maclntyre MF, Allen C, Hansen G, Woodbrook R, et al. The Global Burden of Cancer 2013. JAMA Oncol. 2015;1(4):505-27.

2. Chen W, Zheng R, Baade PD, Zhang S, Zeng H, Bray F, Jemal A, Yu XQ, He J. Cancer statistics in China, 2015. CA Cancer J Clin. 2016;66(2):115-32.

3. Zabaleta J. Multifactorial etiology of gastric cancer. Methods Mol Biol. 2012;863:411-35.

4. Persson C, Canedo P, Machado JC, El-Omar EM, Forman D. Polymorphisms in inflammatory response genes and their association with gastric cancer: a HuGE systematic review and meta-analyses. Am J Epidemiol. 2011;173(3):259-70.

5. He BS, Pan YQ, Xu YF, Zhu C, Qu LL, Wang SK. Polymorphisms in interleukin-1B (IL-1B) and interleukin 1 receptor antagonist (IL-1RN) genes associate with gastric cancer risk in the Chinese population. Dig Dis Sci. 2011;56(7):2017-23.

6. He B, Zhang Y, Pan Y, Xu Y, Gu L, Chen L, Wang S. Interleukin 1 beta (IL 1B) promoter polymorphism and cancer risk: evidence from 47 published studies. Mutagenesis. 2011;26(5):637-42.

7. Yellapa A, Bahr JM, Bitterman P, Abramowicz JS, Edassery SL, Penumatsa K, Basu S, Rotmensch J, Barua A. Association of interleukin 16 with the development of ovarian tumor and tumor-associated neoangiogenesis in laying hen model of spontaneous ovarian cancer. Int J Gynecol Cancer. 2012;22(2):199-207.

8. Mathy NL, Scheuer W, Lanzendorfer M, Honold K, Ambrosius D, Norley S, Kurth R. Interleukin-16 stimulates the expression and production of pro-inflammatory cytokines by human monocytes. Immunology 2000;100(1):63-9.

9. Yang H, Han Y, Wu L, Wu C. Diagnostic and prognostic value of serum interleukin16 in patients with gastric cancer. Mol Med Rep. 2017;16(6):9143-8.

10. Blobe GC, Schiemann WP, Lodish HF. Role of transforming growth factor beta in human disease. N Engl J Med. 2000;342(18):1350-8.

11. Ishimoto T, Miyake K, Nandi T, Yashiro M, Onishi N, Huang KK, Lin SJ, Kalpana R, Tay ST, Suzuki Y, et al. Activation of transforming growth factor beta 1 signaling in gastric cancer-associated fibroblasts increases their motility, via expression of rhomboid 5 homolog 2, and ability to induce invasiveness of gastric cancer cells. Gastroenterology. 2017;153(1):191 e116-204 e116.
12. Ota M, Horiguchi M, Fang V, Shibahara K, Kadota K, Loomis C, Cammer M, Rifkin DB. Genetic suppression of inflammation blocks the tumor-promoting effects of TGF-beta in gastric tissue. Can Res. 2014;74(9):2642-51.

13. Tas F, Yasasever CT, Karabulut S, Tastekin D, Duranyildiz D. Serum transforming growth factor-beta1 levels may have predictive and prognostic roles in patients with gastric cancer. Tumour Biol. 2015;36(3):2097-103.

14. Hu WQ, Wang LW, Yuan JP, Yan SG, Li JD, Zhao HL, Peng CW, Yang GF, Li $Y$. High expression of transform growth factor beta 1 in gastric cancer confers worse outcome: results of a cohort study on 184 patients. Hepatogastroenterology. 2014;61(129):245-50.

15. Chen J, Miao L, Jin G, Ren C, Ke Q, Qian Y, Dong M, Li H, Zhang Q, Ding Y, et al. TGFBR1 tagging SNPs and gastric cancer susceptibility: a two-stage case-control study in Chinese population. Mol Carcinog. 2014;53(2):109-16.

16. Chang WW, Zhang L, Su H, Yao YS. An updated meta-analysis of transforming growth factor-beta1 gene: three polymorphisms with gastric cancer. Tumour Biol. 2014;35(4):2837-44.

17. Guo W, Dong Z, Guo Y, Chen Z, Yang Z, Kuang G. Association of polymorphisms in transforming growth factor-beta receptors with susceptibility to gastric cardia adenocarcinoma. Mol Biol Rep. 2012;39(4):4301-9.

18. Kutikhin AG. Impact of Toll-like receptor 4 polymorphisms on risk of cancer. Hum Immunol. 2011;72(2):193-206.

19. Stubljar D, Jeverica S, Jukic T, Skvarc M, Pintar T, Tepes B, Kavalar R, Stabuc $B$, Peterlin B, Ihan A. The influence of cytokine gene polymorphisms on the risk of developing gastric cancer in patients with Helicobacter pylori infection. Radiol Oncol. 2015;49(3):256-64

20. Qadri Q, Rasool R, Afroze D, Naqash S, Gulzar GM, Yousuf A, Siddiqi MA, Shah ZA. Study of TLR4 and IL-8 gene polymorphisms in H. pylori-induced inflammation in gastric cancer in an ethnic Kashmiri population. Immunol Invest. 2014;43(4):324-36.

21. Santini D, Angeletti S, Ruzzo A, Dicuonzo G, Galluzzo S, Vincenzi B, Calvieri A, Pizzagalli F, Graziano N, Ferraro E, et al. Toll-like receptor 4 Asp299Gly and Thr399lle polymorphisms in gastric cancer of intestinal and diffuse histotypes. Clin Exp Immunol. 2008;154(3):360-4.

22. He BS, Sun HL, Xu T, Pan YQ, Lin K, Gao TY, Zhang ZY, Wang SK. Association of genetic polymorphisms in the LnCRNAs with gastric cancer risk in a chinese population. J Cancer. 2017;8(4):531-6.

23. Slattery ML, Trivellas A, Pellatt AJ, Mullany LE, Stevens JR, Wolff RK, Herrick JS. Genetic variants in the TGFbeta-signaling pathway influence expression of miRNAs in colon and rectal normal mucosa and tumor tissue. Oncotarget. 2017;8(10):16765-83.

24. Nicoloso MS, Sun H, Spizzo R, Kim H, Wickramasinghe P, Shimizu M, Wojcik SE, Ferdin J, Kunej T, Xiao L, et al. Single-nucleotide polymorphisms inside microRNA target sites influence tumor susceptibility. Can Res. 2010;70(7):2789-98.

25. Valle L, Serena-Acedo T, Liyanarachchi S, Hampel H, Comeras I, Li Z, Zeng Q, Zhang HT, Pennison MJ, Sadim M, et al. Germline allele-specific expression of TGFBR1 confers an increased risk of colorectal cancer. Science. 2008;321(5894):1361-5.

26. Castano-Rodriguez N, Kaakoush NO, Pardo AL, Goh KL, Fock KM, Mitchell HM. Genetic polymorphisms in the Toll-like receptor signalling pathway in Helicobacter pylori infection and related gastric cancer. Hum Immunol. 2014;75(8):808-15.

27. Huang L, Yuan K, Liu J, Ren X, Dong X, Tian W, Jia Y. Polymorphisms of the TLR4 gene and risk of gastric cancer. Gene. 2014;537(1):46-50.

28. Yamaguchi T, Fushida S, Yamamoto Y, Tsukada T, Kinoshita J, Oyama K, Miyashita T, Tajima H, Ninomiya I, Munesue S, et al. Low-dose paclitaxel suppresses the induction of $\mathrm{M} 2$ macrophages in gastric cancer. Oncol Rep. 2017;37(6):3341-50.

29. Li G, Wang Z, Ye J, Zhang X, Wu H, Peng J, Song W, Chen C, Cai S, He Y, et al. Uncontrolled inflammation induced by AEG-1 promotes gastric cancer and poor prognosis. Can Res. 2014;74(19):5541-52.

30. Zonneville J, Safina A, Truskinovsky AM, Arteaga CL, Bakin AV. TGF-beta signaling promotes tumor vasculature by enhancing the pericyteendothelium association. BMC cancer. 2018;18(1):670. 